\title{
Association of body composition with sarcopenic obesity in elderly women
}

This article was published in the following Dove Press journal:

International Journal of General Medicine

II January 2013

Number of times this article has been viewed

\author{
Alessandro Oliveira Silva ${ }^{1,2}$ \\ Margô Gomes Oliveira \\ Karnikowski ${ }^{3}$ \\ Silvana Schwerz Funghetto ${ }^{3}$ \\ Marina Morato Stival ${ }^{3}$ \\ Ricardo Moreno Lima ${ }^{3}$ \\ Jéssica Cardoso de Souza' \\ James Wilfred Navalta ${ }^{4}$ \\ Jonato Prestes' \\ 'Catholic University of Brasilia, \\ Brasilia, DF, Brazil; ${ }^{2}$ Center University \\ of Brasilia, Brasilia, DF, Brazil; \\ ${ }^{3}$ University of Brasilia, Brasilia, DF, \\ Brazil; ${ }^{4}$ University of Nevada, Las \\ Vegas, NV, USA
}

\begin{abstract}
The aim of the present study was to investigate the prevalence of sarcopenic obesity and its association with obesity and sarcopenia in elderly Brazilian women. Two hundred and seventy-two sedentary women with a mean age of $66.75 \pm 5.38$ years were recruited for participation in this study. Obesity was determined by both body mass index and dual-energy X-ray absorptiometry (DXA) evaluations. Sarcopenic obesity diagnosis was established from the ratio between fat-free mass and body surface area as obtained by DXA. There was no association of obesity with sarcopenic obesity $(P=0.424)$. In contrast, sarcopenia was significantly related to sarcopenic obesity $(P<0.001)$, although most of the elderly women with sarcopenia $(n=171)$ did not exhibit sarcopenic obesity. These results highlight the importance of diagnosing sarcopenic obesity as elderly women exhibiting sarcopenia could be either eutrophic or obese.
\end{abstract}

Keywords: sarcopenic obesity, aging, obesity, sarcopenia, health

\section{Introduction}

Aging of the population is a worldwide phenomenon that is accompanied by a series of modifications to several physiological parameters, such as a progressive increase in fat mass and a decrease in lean body mass. ${ }^{1}$ However, these alterations are not linear and must be constantly monitored..$^{2-4}$ In elderly individuals, changes in body composition result in the prevalence of overweight and obesity combined with a loss of muscle mass and strength; this has recently been defined as sarcopenic obesity. ${ }^{5-7}$ Sarcopenic obesity is associated with functional limitations and increased mortality. ${ }^{8}$

Among the consequences of obesity in elderly individuals are increased risk of cardiometabolic complications, physical incapacity, sexual dysfunction, urinary incontinence, depression, type 2 diabetes, arthritis, decreased cognitive function, dementia, and compromised health-related quality of life. ${ }^{9-12}$ Apart from this, the loss of muscle mass associated with the aging process results in muscle weakness, increased fall risk, and fat infiltration in the skeletal muscle. ${ }^{13,14}$

In this sense sarcopenia is defined as a decline in muscle mass associated with spinal shortening and a decrease in muscle strength and functionality. ${ }^{5,15}$ These deleterious effects seem to result from a complex interaction of innervation disturbances, decreased hormonal levels, and increased inflammatory mediators during aging. ${ }^{1,16,17}$ The reduction in muscle mass and strength is responsible for the decrease in mobility, decreased functional capacity, and increase in dependency; there are also economic and social costs. ${ }^{4,6,14}$

The impact of sarcopenic obesity on the health of older individuals is poorly understood. Thus, the present study aimed to investigate the associations between body composition profile and sarcopenia prevalence in elderly sedentary Brazilian women. Our 
initial hypothesis was that a proper diagnosis of sarcopenic obesity would be independent of the nutritional state.

\section{Methods}

This transversal and analytical study consisted of 272 elderly women from a local community located in the Federal District, Brazil. Participants were not specifically representative of the Brazilian population and were recruited on a voluntary basis from the local community from posters and lectures about the study. Subjects' characteristics are presented in Table 1. Individuals visited the laboratory on two occasions. On the first visit they completed an anamnesis form and physical activity questionnaire and were subjected to anthropometric measures. The following day they were subjected to dual-energy X-ray absorptiometry (DXA) analysis.

Inclusion criteria were age $\geq 60$ years, sedentary females, and completion of all anthropometric testing. Sedentarism was determined by the International Physical Activity Questionnaire. Individuals with inflammatory, rheumatic, or autoimmune conditions or use of medications (beta blockers and metformin) that could modulate body composition were excluded. The local Ethics Committee for Human Research of the Catholic University of Brasilia approved the methodology of the present study, and all participants signed an informed consent document. The procedures were in accordance with guidelines for experimentation with human participants. Additionally, the study met the ethical standards proposed by the International Journal of Sports Medicine. ${ }^{18}$

\section{Body composition determination}

The determination of body composition was completed using DXA (General Electric-GE model 8548 BX1L, year 2005, Lunar DPX type, software Encore 2005; Rommelsdorf, Germany). The appendicular fat-free mass (AFFM) was determined by the sum of the fat-free mass from the lower and upper body.

\section{Sarcopenic obesity determination}

Sarcopenic obesity was determined by body composition measured by the DXA method according to Oliveira et al. ${ }^{19}$

Table I Subjects' characteristics

\begin{tabular}{lr}
\hline Age (years) & $66.75 \pm 5.38$ \\
Height $(\mathrm{cm})$ & $152.20 \pm 0.05$ \\
Body mass index $\left(\mathrm{kg} / \mathrm{m}^{2}\right)$ & $28.56 \pm 4.00$ \\
Fat-free mass $(\mathrm{kg})$ & $24.64 \pm 7.70$ \\
Fat mass $(\%)$ & $41.24 \pm 4.26$ \\
\hline
\end{tabular}

Notes: Data are presented as mean \pm standard deviation of the mean; $n=272$.
Individuals with residual values $\geq-3.4$ were classified as presenting an inadequate FFM in reference to the body surface. This condition is defined as sarcopenic obesity.

The identification of sarcopenia was based on the values proposed by Baumgartner et al, ${ }^{3}$ which define female individuals as sarcopenic with an AFFM $<5.45 \mathrm{~kg} / \mathrm{m}^{2}$. Relative AFFM is calculated by dividing the AFFM by the height squared.

Obesity was determined by DXA and body mass index (BMI). Body fat percentage values were distributed according to the recommendations of the National Institute of Diabetes and Digestive and Kidney Diseases, ${ }^{20}$ assuming a cut-off point of $32 \%$ for women. Obesity levels determined by BMI (body mass/height ${ }^{2}$ ) followed the proposal of Lipschitz, ${ }^{21}$ assuming a cut-off point of $27 \mathrm{~kg} / \mathrm{m}^{2}$ for women. Based on differences between individuals aged 60 to 69 years and those above 70 years, the participants were divided into two age groups.

\section{Statistical analysis}

Data are presented as absolute and relative frequency. The Kolmogorov-Smirnov normality test and a homoscedasticity test (Mauchly) were used to test the normal distribution of the data. The associations between variables were verified by the $\chi^{2}$ test for individuals, Mann-Whitney test for variables with two levels, and Kruskal-Wallis test for variables with more than two levels. The significance value adopted was $P \leq 0.05$. The Statistical Package for the Social Sciences ([SPSS] v.19; IBM Corporation, Armonk, NY) was used for analyses.

\section{Results}

Characterization of the nutritional state by BMI revealed that $65.1 \%(n=177)$ were eutrophic, while all women were classified as obese by DXA $(n=272)$ with different degrees of severity; most of them exhibited morbid obesity (Table 2). The majority of women $(61.76 \%)$ were classified as morbid obesity, while $34.2 \%(n=93)$ presented sarcopenic obesity. Among this group, 63 were aged between 60 to 69 years.

Table 2 Characterization of obesity severity in elderly sedentary women considering the body composition determined by dualenergy X-ray absorptiometry

\begin{tabular}{lllll}
\hline Age & \multicolumn{2}{l}{ Degrees of obesity } & \multirow{2}{*}{ Total } \\
\cline { 2 - 4 } & $\begin{array}{l}\text { Mild and } \\
\text { moderate }\end{array}$ & Elevated & Morbid & \\
\hline $60-69$ years & $5(2.6 \%)$ & $57(29.53 \%)$ & $131(67.87 \%)$ & $193(100 \%)$ \\
$\geq 70$ years & $8(10.14 \%)$ & $34(43.03 \%)$ & $37(46.83 \%)$ & $79(100 \%)$ \\
Total & $13(4.79 \%)$ & $91(33.45 \%)$ & $168(61.76 \%)$ & $272(100 \%)$ \\
\hline
\end{tabular}


Women between 60 to 69 years exhibited a higher body fat percentage $(P=0.004)$ and obesity determined by body composition $(P=0.001)$ measured by DXA as compared with women above 70 years, according to the classification of the National Institute of Diabetes and Digestive and Kidney Diseases..$^{20}$ There was no statistically significant difference between age groups in the parameters determined by BMI $(P=0.07)$, sarcopenic obesity $(P=0.40)$, or sarcopenia $(P=0.40)$.

Thirty-nine percent of the eutrophic elderly women determined by BMI exhibited sarcopenic obesity, while $23.1 \%$ of those classified with mild and moderate obesity by DXA presented sarcopenic obesity (Table 3). There was no association with sarcopenic obesity independent of obesity severity determined by DXA (Table 3 ). However, there was a negative association between sarcopenia and sarcopenic obesity, hence most of the elderly women with sarcopenia did not present sarcopenic obesity (Table 3).

Independent of obesity or eutrophy, there was an association between sarcopenia and BMI (Table 4). Apart from this, there was an association between sarcopenia and obesity determined by DXA, and as obesity increased in severity the prevalence of sarcopenia increased (Table 4).

\section{Discussion}

The combination of sarcopenia and obesity (known as sarcopenic obesity) is an important public health problem that induces fragility in the elderly.,22,23 The current incidence of sarcopenic obesity in elderly Brazilian women suggests it plays a role as an important negative factor that counteracts a successful aging process. In comparison, an elderly Mexican

Table 3 Associations of sarcopenic obesity with obesity determined by BMI and DXA and by relative AFFM in elderly Brazilian women

\begin{tabular}{|c|c|c|c|c|c|}
\hline & \multicolumn{4}{|c|}{ Sarcopenic obesity } & \multirow[t]{3}{*}{$P$} \\
\hline & \multicolumn{2}{|c|}{ Yes } & \multicolumn{2}{|l|}{ No } & \\
\hline & $\mathbf{N}$ & $\%$ & $\mathbf{N}$ & $\%$ & \\
\hline BMI & & & & & 0.023 \\
\hline Obesity & 24 & 25.3 & 71 & 74.7 & \\
\hline Eutrophic & 69 & 39.0 & 108 & 61.0 & \\
\hline DXA & & & & & 0.424 \\
\hline Mild and moderate obesity & 3 & 23.1 & 10 & 76.9 & \\
\hline Severe obesity & 35 & 38.5 & 56 & 61.5 & \\
\hline Morbid obesity & 55 & 32.7 & 113 & 67.3 & \\
\hline Relative AFFM kg/m² $<5.45$ & & & & & $<0.001$ \\
\hline Sarcopenic & 27 & 13.6 & 171 & 86.4 & \\
\hline Nonsarcopenic & 66 & 89.2 & 8 & 10.8 & \\
\hline
\end{tabular}

Abbreviations: AFFM, appendicular fat-free mass; BMI, body mass index; DXA, dual-energy X-ray absorptiometry.
Table 4 Associations of sarcopenia with obesity determined by $\mathrm{BMI}$ and DXA in sedentary elderly women

\begin{tabular}{|c|c|c|c|c|c|}
\hline & \multicolumn{4}{|c|}{ Sarcopenia } & \multirow[t]{3}{*}{$P$} \\
\hline & \multicolumn{2}{|l|}{$\overline{\text { Yes }}$} & \multicolumn{2}{|l|}{ No } & \\
\hline & $\mathbf{N}$ & $\%$ & $\mathbf{N}$ & $\%$ & \\
\hline $\mathrm{BMI}$ & & & & & 0.047 \\
\hline Obesity & 76 & 80.0 & 19 & 20.0 & \\
\hline Eutrophic & 122 & 68.9 & 55 & 31.1 & \\
\hline DXA & & & & & 0.044 \\
\hline Mild and moderate obesity & 7 & 53.8 & 6 & 46.2 & \\
\hline Severe obesity & 59 & 64.8 & 32 & 35.2 & \\
\hline Morbid obesity & 132 & 78.6 & 36 & 21.4 & \\
\hline
\end{tabular}

Abbreviations: BMI, body mass index; DXA, dual-energy X-ray absorptiometry.

population showed a higher incidence of sarcopenic obesity $(48 \%)^{3}$ compared with our results. The reduction in muscle mass (sarcopenia) that accompanies the normal aging process is also associated with increments in fat mass. With the concurrent increment in elderly people as reported by the Brazilian Institute of Geography and Statistics ${ }^{24}$ and the prevalence of sarcopenic obesity in Brazilians, a higher fragility could be expected in this population. ${ }^{25,26}$ Our results suggest the necessity of proper diagnosis of sarcopenic obesity independent of the nutritional state, such as muscle cross-sectional area, because the eutrophic status or the different obesity levels do not influence the diagnosis of sarcopenic obesity.

Our study indicates that a sedentary lifestyle may be an additional risk factor for both overweight and obesity, highlighting the concurrent muscular force loss as previously suggested..$^{27}$ This is in accordance with previous literature. ${ }^{28}$ The diagnosis for obesity requires the utilization of various methods because BMI has been suggested to be inappropriate for this purpose in the elderly. ${ }^{10}$ Moreover, the current results suggest some discrepancies between BMI and DXA methods regarding the nutritional status of participants. Thus, eutrophic elderly women as determined by BMI were classified as obese with various severity levels with the employment of DXA, confirming the previous observations of Pahor et al. ${ }^{29}$ In this regard, BMI has demonstrated some limitations because of the concurrent lean body mass loss and fat mass gain observed in the elderly. ${ }^{10}$ Furthermore, all participants of the present study exhibited various levels of obesity, thus confirming the findings of previous studies in Brazilian populations. ${ }^{30,31}$ Although BMI has been widely used in population studies, this method considers only height and body mass. On the other hand, DXA is considered a "gold-standard" method to estimate body composition, despite the high cost. In this sense, a higher sensitivity of DXA to estimate body composition would be expected. 
Adipose tissue is currently recognized as an important metabolic and hormonal secretory organ with more than 50 product molecules identified. ${ }^{1}$ Subsequently, when there is an increase in adipose tissue, the impact of these molecules is also augmented, thus favoring the development of insulin resistance, type II diabetes, atherosclerosis, and metabolic syndrome and therefore impacting the health of older individuals. ${ }^{8,32,33}$

With the current results it was possible to verify an overestimation of muscle mass as a consequence of not taking into account the true differences in water, bone mass, and FFM, as the elderly have demonstrated an excessive extracellular fluid accumulation. ${ }^{29}$ This syndrome is associated with a progressive loss of muscle force and mass with subsequent lower physical capacity and quality of life, and hence the current results should be considered for further interventions in this population.

Newman et $\mathrm{al}^{34}$ emphasized the need to consider fat mass when diagnosing sarcopenia. The premise is based on the fact that individuals with high fat mass also demonstrate a high FFM. Therefore, individuals with high fat mass and subsequently high FFM would not be diagnosed as sarcopenic, independently of its influence on total body mass or functional capacity. In order to adjust FFM with fat mass, Newman et $\mathrm{al}^{34}$ proposed a method based on the residuals of a regression equation that predicts AFFM from fat mass and height; this was helpful in the diagnosis of sarcopenic obesity in the current study.

The limitations of the present study are the reduced number of participants and lack of additional measures, such as calf circumference and other metabolic parameters, that would certainly be of interest.

\section{Conclusion}

In summary, the present study observed a critical relationship between sarcopenia and obesity in an elderly female population. The combination of sarcopenic obesity may have a dynamic negative impact on the aging process in the elderly, and thus the ability to correctly diagnose this condition becomes important. Further studies are needed for the diagnosis of sarcopenic obesity as well for understanding its etiology and clinical impact, specifically in the elderly population of developing countries where public health systems are not prepared for the demands of this population sector.

\section{Acknowledgments}

The authors thank the Graduate Department of the University of Brasilia for financial support and Daniel Boullosa, $\mathrm{PhD}$, for revising the manuscript.

\section{Disclosure}

The authors report no conflicts of interest in this work.

\section{References}

1. Peake J, Della Gatta P, Cameron-Smith D. Aging and its effects on inflammation in skeletal muscle at rest and following exercise-induced muscle injury. Am J Physiol Regulatory Integrative Comp Physiol. 2010; 298:R1485-R1495.

2. Baumgartner RN. Body composition in healthy aging. Ann N Y Acad Sci. 2000;904:437-448.

3. Baumgartner RN, Koehler KM, Gallagher D, et al. Epidemiology of sarcopenia among the elderly in New Mexico. Am J Epidemiol. 1998; 147:755-763.

4. Hughes VA, Frontera WR, Roubenoff R, Evans WJ, Singh MAF. Longitudinal changes in body composition in older men and women: role of body weight change and physical activity. Am J Clin Nutr. 1992;76:473-481.

5. Cruz-Jentoft AJ, Baeyens JP, Bauer JM, et al. Sarcopenia: European consensus on definition and diagnosis report of the European Working Group on Sarcopenia in Older People. Age Ageing. 2010;39: 412-423.

6. Narici MV, Maffulli N. Sarcopenia: characteristics, mechanisms and functional significance. Br Med Bull. 2010;95:139-159.

7. Zamboni M, Mazzali G, Fantin F, Rossi A, Di Francesco V. Sarcopenic obesity: a new category of obesity in the elderly. Nutr Metab Cardiovasc Dis. 2008;18:339-388.

8. Stenholm S, Harris TB, Rantanen T, Visser M, Kritchevsky SB, Ferrucci L. Sarcopenic obesity - definition, etiology and consequences. Curr Opin Clin Nutr Metab Care. 2008;11:693-700.

9. Gustafson D, Rothenberg E, Blennow K, Steen B, Skoog I. An 18-year follow-up of overweight and risk of Alzheimer disease. Arch Intern Med. 2003;163:1524-1528.

10. Han TS, Tajar A, Lean ME. Obesity and weight management in the elderly. Br Med Bull. 2011;97:169-196.

11. Rosengren A, Skoog I, Gustafson D, Wilhelmsen L. Body mass index, other cardiovascular risk factors, and hospitalization for dementia. Arch Intern Med. 2005;165:321-326.

12. Whitmer RA, Gunderson EP, Barrett-Connor E, Quesenberry CP Jr, Yaffe K. Obesity in middle age and future risk of dementia: a 27 year longitudinal population based study. BMJ. 2005;330:1360.

13. Evans WJ. Skeletal muscle loss: cachexia, sarcopenia, and inactivity. Am J Clin Nutr. 2010;91:1123S-1127S.

14. Visser M, Kritchevsky SB, Goodpaster BH, et al. Leg muscle mass and composition in relation to lower extremity performance in men and women aged 70 to 79 : the health, aging and body composition study. J Am Geriatr Soc. 2002;50:897-904.

15. Janssen I. The epidemiology of sarcopenia. Clin Geriatr Med. 2011;27: 355-363.

16. Alemán H, Esparza J, Ramirez FA, Astiazaran H, Payette H. Longitudinal evidence on the association between interleukin- 6 and C-reactive protein with the loss of total appendicular skeletal muscle in free-living older men and women. Age Ageing. 2011;40:469-475.

17. Cederholm TE, Bauer JM, Boirie Y, Schneider SM, Sieber CC, Rolland Y. Toward a definition of sarcopenia. Clin Geriatr Med. 2011; 27:341-353.

18. Harriss DJ, Atkinson G. Ethical standards in sport and exercise science research. Int J Sports Med. 2009;30:701-702.

19. Oliveira RJ, et al. Identification of sarcopenic obesity in postmenopausal women: a cutoff proposal. Braz J Med Biol Res [online]. 2011;44(11): 1171-1176. Epub October 13, 2011. ISSN 1414-431X. Available from: http://dx.doi.org/10.1590/S0100-879X2011007500135.

20. National Institute of Diabetes and Digestive and Kidney Diseases. Understanding Adult Obesity (NIH Publ no 94-3680). Rockville, MD: National Institute of Health; 1993.

21. Lipschitz DA. Screening for nutritional status in the elderly. Prim Care. 1994;21:55-67. 
22. Baumgartner RN, Wayne SJ, Waters Dl, Janssen I, Gallagher D, Morley JE. Sarcopenic obesity predicts instrumental activities of daily living disability in the elderly. Obes Res. 2004;12:1995-2004.

23. Monteiro M, Gabriel R, Aranha J, Neves Castro M, Sousa M, Moreira M. Influence of obesity and sarcopenic obesity on plantar pressure of postmenopausal women. Clin Biomech. 2010;25:461-467.

24. Brazilian Institute of Geographics and Statistics. [Synthesis of Social Indicators - An Analysis of Life Conditions of Brazilian Population 2010]. Rio de Janeiro: Instituto Brasileiro de Geografia e Estatística (IBGE); 2010. Available from: http://www.ibge.gov.br/ home/estatistica/populacao/condicaodevida/indicadoresminimos/ sinteseindicsociais2010/SIS_2010.pdf. Accessed July 28, 2012. Portuguese.

25. Kalache A. The world is aging: a pact of social solidarity is an imperative. Cien Saude Colet. 2008;13:1107-1111.

26. Veras R. Population aging and health information from the National Household Sample Survey: contemporary demands and challenges. Introduction. Cad Saude Publica. 2007;23:2463-2466. Portuguese.

27. Duvigneaud N, Matton L, Wijndaele K, et al. Relationship of obesity with physical activity, aerobic fitness and muscle strength in Flemish adults. J Sports Med Phys Fitness. 2008;48:201-210.
28. Lamonte MJ, Blair SN. Physical activity, cardiorespiratory fitness, and adiposity: contributions to disease risk. Curr Opin Clin Nutr Metab Care. 2006;9:540-546.

29. Pahor M, Manini T, Cesari M. Sarcopenia: clinical evaluation, biological markers and other evaluation tools. J Nutr Health Aging. 2009;13: 724-728.

30. Lima RM, Bezerra LM, Rabelo HT, et al. Fat-free mass, strength, and sarcopenia are related to bone mineral density in older women. J Clin Densitom. 2009; 12:35-41.

31. Silva AO, Oliveira HB, Tavares AB, Funghetto SS, Prestes J, Karnikowski MGO. Comparison of inflammatory, metabolic, and anthropometric parameters in elderly women with and without insulin resistance. Res Aging. 2012;34:261-274.

32. Harrington J, Lee-Chiong T. Obesity and aging. Clin Chest Med. 2009;30:609-614.

33. Houston DK, Nicklas BJ, Zizza CA. Weighty concerns: the growing prevalence of obesity among older adults. J Am Diet Assoc. 2009;109:1886-1895.

34. Newman AB, Kupelian V, Visser M, et al; Health ABC Study Investigators. Sarcopenia: alternative definitions and associations with lower extremity function. J Am Geriatr Soc. 2003;51:1602-1609.
International Journal of General Medicine

\section{Publish your work in this journal}

The International Journal of General Medicine is an international peer-reviewed open-access journal that focuses on general and internal medicine, pathogenesis, epidemiology, diagnosis, monitoring and treatment protocols. The journal is characterized by the rapid reporting of reviews, original research and clinical studies across all disease areas.

\section{Dovepress}

A key focus is the elucidation of disease processes and management protocols resulting in improved outcomes for the patient.The manuscript management system is completely online and includes a very quick and fair peer-review system. Visit http://www.dovepress.com/ testimonials.php to read real quotes from published authors.

Submit your manuscript here: http://www.dovepress.com/international-journal-of-general-medicine-journal 